ARTE TRANSFORMADOR.

LA UTILIDAD SOCIAL DE LA PRODUCCIÓN CULTURAL

\title{
TRANSFORMER ART.
}

THE SOCIAL UTILITY OF CULTURAL PRODUCTION

\section{Yuri Alberto Aguilar Hernández}

Universidad Nacional Autónoma de México, México

yuri.escultor@comunidad.unam.mx

Recepción: 30 de julio de 2018 • Aceptación: 1 de octubre de 2018

\section{RESUMEN}

Pensar el arte ampliando su campo de acción más allá del ámbito profesional, nos permite internarnos en el espacio social y reflexionar en la utilidad social del arte. Un arte que indaga sobre la multidimensionalidad vinculante entre arte y sociedad, comenzando con la noción de la escultura social, y continuando algunas prácticas instituyentes actuales. Talleres comunitarios, arquitecturas colectivas y tácticas urbanas son las herramientas artísticas utilizadas para la transformación social de algunas comunidades de Tlalpan y Xochimilco en la Ciudad de México. Donde la colaboración y producción cultural se entremezclan para potenciar y describir las posibilidades de agencia que tiene el arte actual. Metodológicamente se plantea las prácticas artísticas como formas de experimentación y la observación participante como herramientas de reflexión y análisis.

Palabras clave: utilidad del arte, transformación social, talleres comunitarios, escultura social, arquitecturas colectivas y tácticas urbanas.
ABSTRACT

Thinking about art, broadening its field of action beyond the professional field, allows us to enter the social space and reflect on the social utility of art. An art that explores the binding multidimensionality between art and society, starting with the notion of social sculpture, and continuing some current instituting practices. Community workshops, collective architectures and urban tactics are the artistic tools used for the social transformation of some Tlalpan and Xochimilco communities in Mexico City. Where collaboration and cultural production are intermingled to enhance and describe the possibilities of agency that has the current art. Methodologically, artistic practices are considered as forms of exploration and participant observation as tools for reflection and analysis.

Keywords: usefulness of art, social transformation, community workshops, social sculpture, collective architectures and urban tactics. 
Comprendo la escultura social como esa ampliación del arte hacia la noción de producción cultural y sus implicaciones en las relaciones políticas entre las personas, en este contexto, este trabajo da cuenta del desarrollo de algunas experimentaciones ${ }^{1}$ de interacción entre el arte y algunas comunidades, por medio de talleres comunitarios, arquitecturas colectivas y tácticas urbanas. Estas prácticas artísticas alimentaron mi imaginación y trazaron algunas rutas de cognición, reconociéndose como herramientas novedosas para la integración de mi trabajo creativo con entornos comunitarios y colectivos. Metodológicamente es importante pensar el arte como herramienta de indagación, y la observación participante como método de análisis, destacando algunos aspectos pertinentes para la comprensión del arte como acción, el cual plantea: “[...] una manera de realizar investigación que coloca al investigador en medio de la comunidad que está estudiando" (Angrosino, 2012: 20).

[y un] [...] trabajo de campo basado en la observación participante que, idealmente al menos, es un compromiso a largo plazo, ya que el orden subyacente de una sociedad se puede revelar únicamente por la inmersión paciente en la vida de las personas estudiadas (Angrosino, 2012: 22).

Que en este caso son comunidades a las que he pertenecido por más de 10 años. A continuación, invito al lector a compartir estas experiencias que, si bien no agotan la reflexión sobre

1 "Dicho de otra manera, no se puede considerar a la obra contemporánea como un espacio por recorrer (donde el "visitante" es un coleccionista). La obra se presenta ahora como una duración por experimentar, como una apertura posible hacia un intercambio ilimitado" (Bourriaud, 2008: 14). sí mismas, permiten situar la utilidad social de la producción cultural, específicamente del arte/diseño.

\section{Talleres comunitarios "Hazlo tú mismo"}

En el año 2014 comencé a trabajar la ampliación de mi formación disciplinar como escultor, mediante la apertura que la "escultura social" me ofreció, enunciada por Joshep Beuys de la siguiente manera.

En la noción de escultura se ve algo que remite al arte [...] una esencia capaz de crear formas en cada ámbito de la vida y el trabajo, y en todos los campos energéticos de la sociedad [...] El carácter modelador nos lleva al punto en el que hay que hablar de proceso escultural: imprimir una acción en la materia [...] Hay que esculpir una in-formación en ese flujo de aire [...] que pueda dar otra forma de impulsión del sistema [...] En este estadio aparece una ruptura por el productor que se prepara a poner en juego de manera absoluta sus facultades consientes [...] Reconoce que ha producido alguna cosa a través del concepto tradicional del arte y que eso concierne, así, a la sociedad humana [...] la plástica social anticipa lo que - después de la oscuridad de este pasaje crítico, el cual experimentamos actualmente - debe instaurarse gracias a la aportación de todos los valores (Beuys, 1977: 284, 287, 288, 289, 293 y 295).

Pensar desde esta óptica la escultura, como algo que modela el sistema social, ${ }^{2}$ construyendo formas por medio de la

2 Y sobre lo cual se configura más tarde la estética relacional:

La posibilidad de un arte relacional — un arte que tomaría como horizonte teórico la esfera de las interacciones humanas y su contexto social, más que la afirmación de un espacio simbólico autónomo y privadoda cuenta de un cambio radical de los objetivos estéticos, culturales y políticos puestos en juego por el arte moderno (Bourriaud, 2008: 13). 
información y valores, y donde se ponen en juego todas las capacidades del productor, me pareció francamente interesante e inspirador para comenzar estas experimentaciones. Oferté en los kioscos de los pueblos de San Andrés Totoltepec y San Pedro Mártir, así como en el Parque de la Tortuga, en Fuentes de Tepepan de la Ciudad de México, tres talleres comunitarios bajo el título de "Fábrica de Juguetes 'Hazlo Tú mismo (HTM)", planteados desde el siguiente objetivo:

A través de un taller de fabricación de juguetes elaborados con desechos sólidos se ampliará el imaginario ambiental de los niños hacia el reciclado y la reutilización, también se fomentarán ambientes creativos, lúdicos y de convivencia que contribuya a la reconstrucción social de estas comunidades (Aguilar, 2014: 3).

Los talleres se desarrollaron durante septiembre, octubre, noviembre y diciembre del 2014, y fueron de una intensidad que nunca había vivido, debido a que anteriormente en el "Zoomatl" había tenido un fuerte apoyo institucional que me permitía atender de manera más cómoda a los participantes. ${ }^{3}$ Sin, embargo, en esta ocasión la intención era estar soportado por los propios participantes, los cuales son más exigentes que las instituciones, las cuales regularmente se conforman con la entrega en tiempo y forma de los formatos requeridos. ${ }^{4}$ Esta in-

3 Ver el video Varaesculturas, donde se observa el apoyo institucional para la creación participativa de los monumentos. Disponible en: https://youtu.be/WwVgBNfRDl8

4 Estos talleres fueron financiados por el programa de cultura comunitaria de la Delegación de Tlalpan, por medio de la convocatoria 2014:

A Colectivos culturales comunitarios, promotores y gestores culturales independientes, artistas (creadores, intérpretes y talleristas), interesados en desarrollar un proyecto cultural que fomente la cultura tensidad realmente puso a prueba todas mis capacidades, entre ellas, las más exigidas, las de gestión y las docentes.

Transformación y emancipación creativa son dos conceptos que la fábrica HTM produjo, no solamente en el "artistatallerista", sino también en los participantes, que en este caso fueron personas con las que comparto un espacio urbano en las periferias sureñas de la Ciudad de México, forman parte de las comunidades más próximas a mi lugar de residencia de hace más de diez años. Para mí era importante conocer con mayor profundidad las comunidades vecinas a mi localidad, como el pueblo de San Pedro Mártir, en el cual se realizaron algunos hallazgos cualitativos de transformaciones del imaginario y emancipaciones creativas de algunas personas, que me parece pertinente narrar.

A continuación, se reporta el proceso creativo de Adrián, un niño de ocho años que participó en un taller de elaboración de juguetes en el pueblo de San Andres Totoltepec en el 2014. Adrián después de más diez sesiones de preguntarme cada día sobre qué ejercicio o trabajo tenía que hacer, a lo cual siempre les contestaba "lo que tú quieras, qué quieres hacer", y a lo cual se sumaba la intervención de la madre como facilitadora-ayudante. Sorprendente y satisfactoriamente, Ardían llego un día con un empaque de plástico para transportar pan, con la clara idea de lo que quería hacer y cómo hacerlo: una nave espacial. La anterior narración evidencia claramente un salto desde el adiestramiento tradicional hacia la interpretación creativa de los problemas, que la elaboración con materiales de desecho de una nave espacial le planteaba. De tal forma que planteó un procedimiento de cómo

prioritariamente entre niñas, niños, jóvenes mujeres y adultos pertenecientes a las distintas comunidades de la Delegación Tlalpan, fortalezca la identidad, pertenencia y procesos culturales de sus comunidades, en los espacios donde se llevarán a cabo. 
hacer dicho juguete, y que compartió en el taller, sociabilizándolo por medio de trabajo colaborativo, instrucciones aprendidas que fueron transportadas a través de la fábrica HTM a otras personas, y otros espacios comunitarios donde podrán ser utilizados de maneras diversas para otros juguetes.

Estas formas creativas son entendidas en una dimensión comunicativa como las líneas con que se teje la dialógica ${ }^{5}$ comunitaria que promovió la fábrica HTM, estableciendo intercambios donde todos ganan algo, a veces de tamaño pequeño otras no tanto, pero que posibilita la construcción de comunidades por medio de la creatividad, reactivando las habilidades de cooperación a través de lo sociabilización de sus propuestas a interlocutores que escuchan, y observan con atención la manera de proceder del otro, y contestan por medio de otras formas de hacer, partiendo de una serie de estructuras procedimentales generales que a través de su participación en los talleres evolucionan, se desplazan, se hibridan, o se adaptan, como ejercicios de las operaciones constructivas actuales (Pérez, 2003: 59).

5

«Las personas que no observan no pueden conversar.» Estas sabias palabras de un abogado inglés evocan la esencia de la «dialógica», término técnico que designa la atención y la sensibilidad en relación con otras personas. La aguda observación del abogado llama particularmente la atención sobre la participación del oyente en una discusión. Normalmente, cuando hablamos de habilidades de comunicación nos centramos en la manera de realizar una exposición clara, de presentar lo que pensamos o sentimos. Es cierto que para ello se requieren habilidades, pero son de naturaleza declarativa. Saber escuchar requiere otro conjunto de habilidades, las de prestar cuidadosa atención a lo que dicen los demás e interpretarlo antes de responder, apreciando el sentido de los gestos y los silencios tanto como el de los enunciados. Aunque para observar bien tengamos que contenernos, la conversación que de ello resulte será un intercambio más rico, de naturaleza más cooperativa, más dialógica (Sennett, 2012: 30).
En las fotografías siguientes (Imágenes 1 y 2) podemos observar el ambiente de cooperación y participación en los talleres, en los cuales se involucraban entre 10 y 30 personas por cada sesión, personas de todas las edades. Continuando con el análisis reflexivo sobre los participantes, encontré algo desconocido y que me pareció sobresaliente, fue la aparición de estructuras familiares, si bien al interior de los talleres se planteaba el trabajo en comunidad, nunca visualicé la importancia de la familia dentro de estas comunidades, un valor, que, en mi contexto personal, esta desintegrado. Ver a los niños trabajando junto con sus padres, abuelos y tíos fue francamente revelador, e impacto en la manera de concebir también la producción cultural, comprendiendo que siempre implica de una u otra manera a integrantes de mi familia, y sobre lo cual hablaré con mayor detenimiento más adelante, en el apartado sobre trabajo colaborativo.

La emergencia de atender no sólo a los niños en este taller, sino también, a personas adultas y adultas mayores que me solicitaban talleres para elaborar decoraciones y muebles, permitió en el 2015 la expansión de la "Fábrica de Juguetes" hacia su transformación en la "Fábrica de Cultura "Hazlo Tú Mismo"” (Juguetes + Maquetas + Muebles + Decoración).

De tal forma, en 2015 la iniciativa HTM se desarrollaría de igual forma en el kiosco de San Pedro Mártir y en el Parque de la Tortuga, y en una nueva sede del Sistema para el Desarrollo Integral de la Familia de la Ciudad de México (DIF), núm. 19 Juan A. Mateos, en la colonia La Joya, en Tlalpan, que me permitió ampliar mi rango de trabajo con otras comunidades, y profundizar la relación con otras. En el DIF asistían personas de muchos de los pueblos y colonias de Tlalpan, lo cual era algo diferente pero interesante de hacer, en estos talleres fue importante hallar el potencial del arte en la construcción de comunidades de colectividades de desconocidos, para lo cual narraré la experiencia del taller de decorados en el DIF (Imagen 3). 

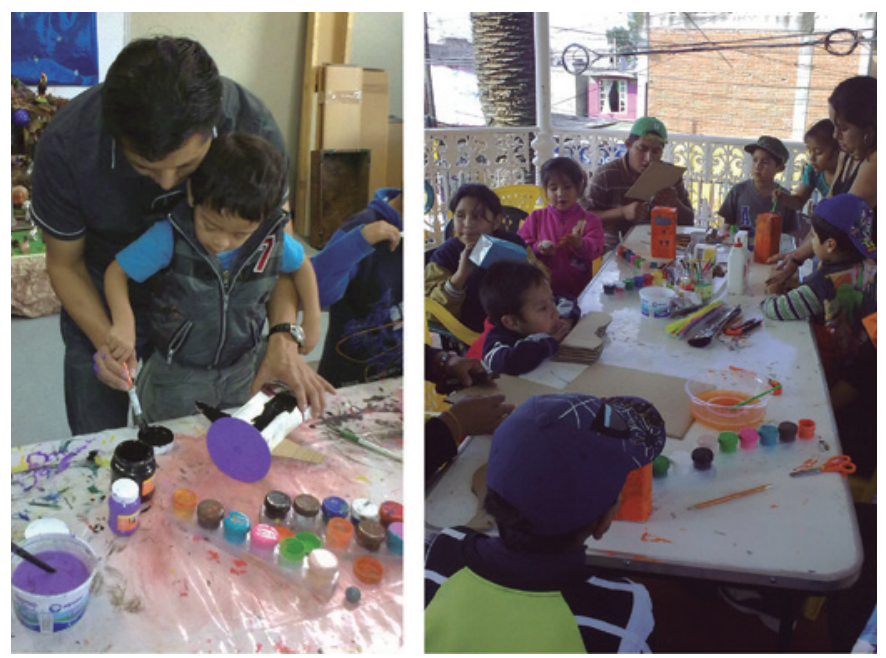

Imágenes 1 y 2. Colaboración familiar en el taller comunitario "Fabrica de Juguetes 'Hazlo tú mismo' " en el Parque de la Tortuga y el San Andrés Totoltepec en el 2014.

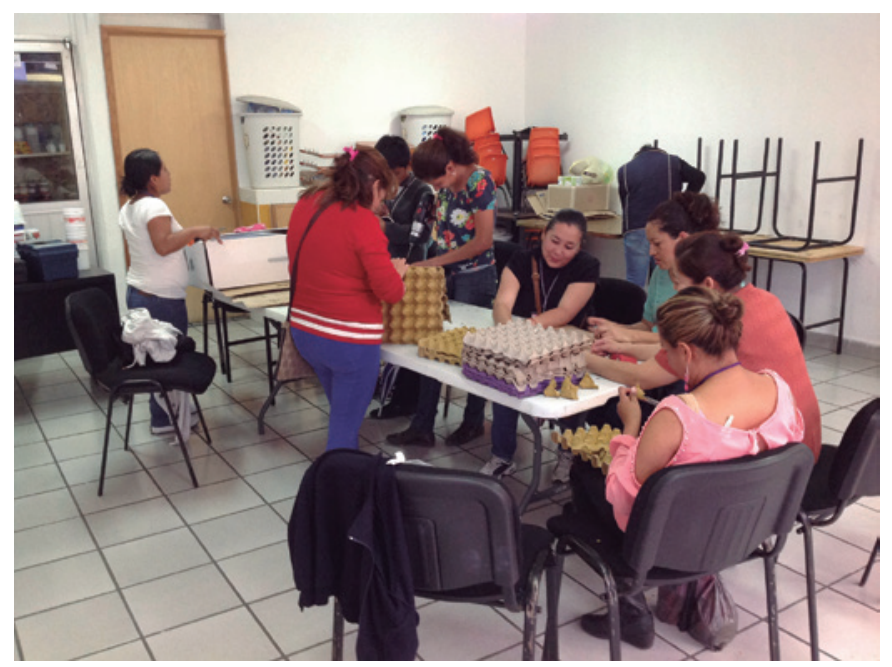

Imagen 3. Taller de decorados de la "Fábrica de Cultura 'Hazlo tú mismo'" en el DIF 19 en la colonia La Joya de la Ciudad de México en 2015.
En la preparación y gestión de este taller establecí un dialogo con Blanca, directora del DIF 19, que me comentó sobre las posibilidades del taller, y me pidió poder atender a las madres, tíos y abuelos de los "niños talento", que asistían al centro para las clases especiales de los niños, que esperaban muriéndose de aburrición a que terminaran las clases. De tal forma, comencé a ofrecer el taller de decorados, donde se fomentó el trabajo colaborativo en la fabricación de lámparas realizadas con desechos sólidos (cartón, latas de aluminio, otros), en el cual, participaron por sesión, a lo largo de tres meses, alrededor de diez mujeres entre 30 y 50 años, y donde se observaron nuevamente el trabajo colaborativo intenso y el empoderamiento creativo de cada participante. Sin embargo, fue impresionante para mí la construcción de comunidad que desarrollaron estas mujeres, lo cual me explico de la siguiente manera.

Después de haber trabajado con ellas en el segundo semestre del 2015, en el taller del 2016 me encontré con la siguiente situación. Ellas habían continuado ejerciendo su derecho a la cultura, y habían exigido la continuidad del taller ya sin facilitador, es decir, sin mí, a lo cual la institución accedió. De tal forma que habían desarrollado un proceso de trabajo autónomo, más vinculado a compartir sus saberes en el tejido y otras actividades vulgarmente llamadas "manualidades", y cuando me acerque a ofrecerles continuar con el taller HTM, más enfocado al uso de desechos sólidos, me dijeron que no estaban interesadas, que ellas ya tenían una serie de actividades que realizar y que mi propuesta no les venía bien. Qué cosa tan extraña para mí, siempre acostumbrado a organizar, ahora estas mujeres no necesitaban de mis habilidades, lo cual después de reflexionarlo un momento, me hizo comprender que, la formación de comunidades creativas algunas veces se realiza en espacios cortos de tiempo, donde los participantes se apropian de los procesos y ya no requieren al facilitador-artista, había un gran despliegue de emancipación. Por esta razón, formamos 
un nuevo taller en otro horario, el cual no llegó a desarrollar las dinámicas colectivas de su taller predecesor, más bien se comportó como todos los demás talleres que había dado, en los pueblos y en Tepepan, cooperativos, familiares y creativos (Imágenes 4 y 5).
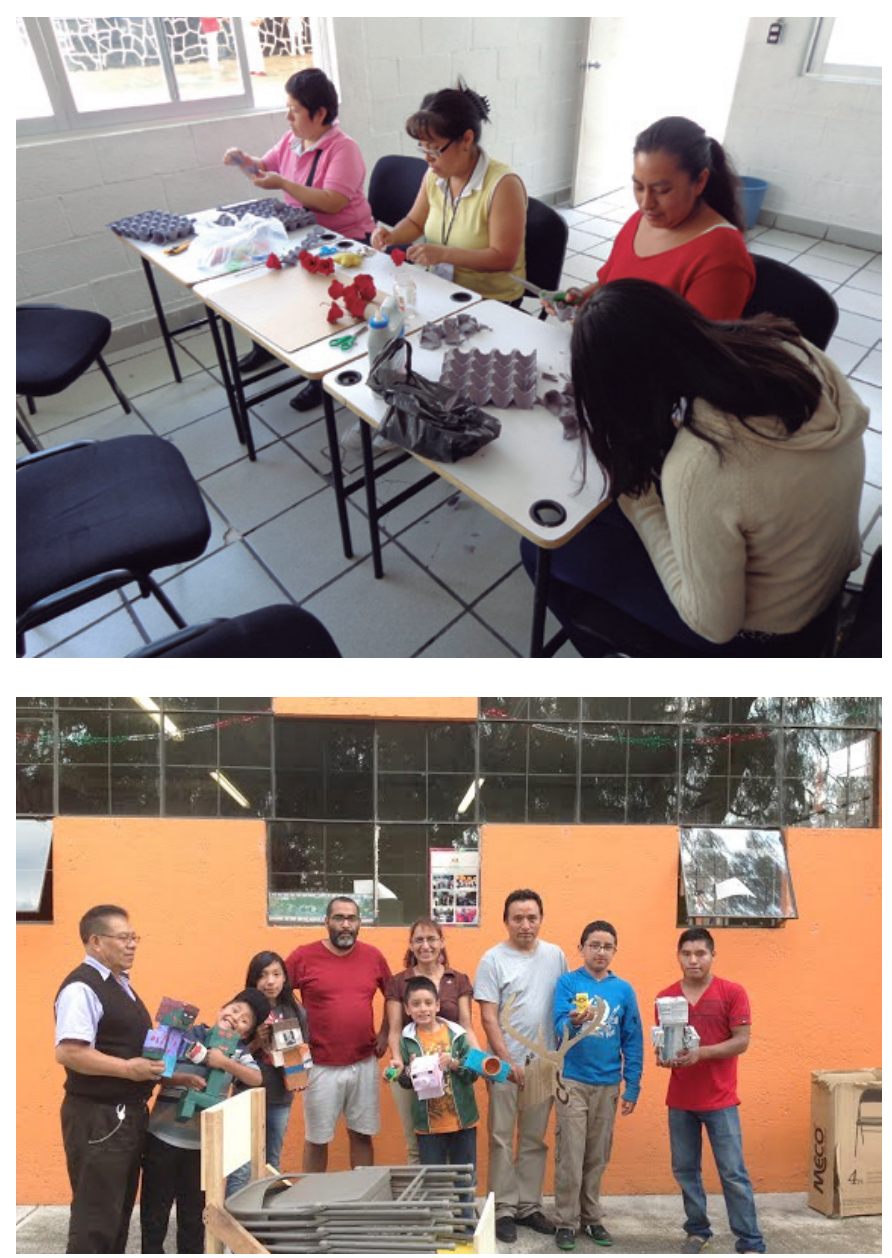

Imágenes 4 y 5. Talleres comunitarios en la "Fabrica de Juguetes 'Hazlo tú mismo' " en el Parque de la Tortuga y DIF 19 en el 2016.

\section{Arquitecturas colectivas}

Las arquitecturas colectivas son una práctica surgida de cuestionar la producción arquitectónica vinculada a la industria de la construcción, que plantea el diseño desde la perspectiva de la planificación. ${ }^{6}$ A diferencia de lo cual, las arquitecturas colectivas se proponen desde la perspectiva del diseño centrado en las personas, ${ }^{7}$ caracterizado desde mi entender, por iniciar procesos de investigación acción participativa a escala humana, en contraposición de la escala masiva de la arquitectura convencional, sumando a ello, la capacidad de movilidad y la inmersión en los contextos sociales.

6 Es una práctica ampliamente difundida en iberoamerica en el encuentro entre artistas, arquitectos y la sociedad civil, como referencia ver Arquitecturaras Colectivas $>$ Red internacional de colectivos. Disponible en: https://arquitecturascolectivas.net/

7 El Diseño Centrado en las Personas (DCP) es un proceso y un conjunto de técnicas que se usan para crear soluciones nuevas para el mundo. Estas soluciones incluyen productos, servicios, espacios, organizaciones y modos de interacción. La razón por la que este proceso se llama "centrado en las personas" es por el hecho de que, en todo momento, está centrado en las personas para quienes se quiere crear la nueva solución. El proceso DCP comienza examinando las necesidades, los sueños y los comportamientos de las personas que se verán beneficiadas por las soluciones resultantes. Se pretende escuchar y entender lo que estas personas desean, lo que necesitan. A eso le llamamos la dimensión de lo que es deseable. A lo largo de todo el proceso de diseño miramos al mundo a través de esta perspectiva. Una vez que hemos identificado lo que es deseable, empezamos a ver nuestras soluciones a través de lo que es factible y lo que es viable. Introducimos estas perspectivas en detalle en las últimas fases del proceso (IDEO, 2015). 
La primera experiencia práctica donde se pusieron en juego estas ideas fue Poliminó (Imágenes 6 y 7), que respondía a los procesos de colaboración que emergían del interior del Grupo de Investigación Acción Interdisciplinaria en Arte y Entorno (GIAE_) ${ }^{8}$ del Posgrado en Artes y Diseño de la UNAM, que planteaban la necesidad de vincular el entorno académico de las investigaciones a contextos comunitarios. En este caso entre la entonces ENAP, ahora FAD Xochimilco y el pueblo de Santiago Tepalcatlalpan, de esta manera y en el marco del Primer encuentro de arte-diseño y proceso sociales, se realizaron diversas actividades en la semana del

8 El trabajo realizado por el Grupo de Investigación Acción Interdisciplinaria en Arte y Entorno [GIAE _ ] desde el año 2012 nos ha permitido construir un espacio de trabajo colectivo en el que participan estudiantes y docentes de la UNAM, y comparte su proceso con otros grupos académicos y colectivos de productores culturales dentro y fuera de México. En este espacio de trabajo se reflexiona sobre los diversos modos en que se produce conocimiento en nuestro campo y articula perspectivas sistémicas, complejas, interdisciplinarias, críticas y trans-epistemológicas en el desarrollo de proyectos de investigación en los programas del programa de posgrado en Artes y Diseño de la UNAM [...] hemos definido tres áreas de trabajo nucleares, asociadas al cultivo de las culturas de conocimiento, información y comunicación, planteadas por el LabComplex como una condición necesaria para la interacción academia - sociedad. Estas tres áreas se denominan de la sigueinte forma: T1. Territorio de conocimiento, T2. Territorio de información, T3. Territorio de comunicación [...] En el T1 se realizan actividades académicas asociadas a los planes y programas del posgrado de la FAD, pero también talleres y seminarios abiertos a actores y comunidades activas más allá de la universitaria. En el T2 se realizan los procesos de documentación, archivo y edición de materiales generados en $\mathrm{T}_{1}$ y $\mathrm{T}_{3}$. En el $\mathrm{T}_{3}$ se preparan las participaciones en charlas, foros, asambleas y se diseñan las acciones colectivas asociadas a la producción y reflexión de $\mathrm{T} 1$ (Aguilar y Serrano, 2017).
18 al 24 de noviembre de $2013,{ }^{9}$ que fueron soportadas por una arquitectura colectiva, que se articulaba y desarticulaba para formar diversidad de espacios habitables (auditorio + foro de discusión + talleres + otros).

El trabajo de diseño se originó como una traducción arquitectónica de la investigación del estudiante de maestría Cesar Cortes: DOSSIER: proyecto de discusión sobre prácticas colaborativas, donde se abrió un proceso de dialogo entre Cesar Cortes, Luis Serrano ${ }^{10}$ y yo, de lo cual resulto Poliminó: espacio dialógico" (Imágenes 6 y 7), que planteaba un diseño modular inspirado en el pentominó (conjunto de combinaciones posibles compuestas por cinco polígonos cúbicos unidos por sus lados), permitiendo trabajar con la experimentar modular de diferentes acomodos utilizada como una plataforma de estructuración de diferentes espacios dialogales, a veces posibilitando la vinculación oral y otras con la acción docente en talleres, o la artística por medio del performance o proyecciones de cine, generando la interacción de las comunidades de la FAD y del Pueblo de Santiago Tepalcatlalpan.

9 Más información en: https:/giaiae.wordpress.com/integrantes/ t3-cultivo-de-cultura-de-comunicacion/t3_f-intervencion/1er-encuentro-de-arte-diseno-y-procesos-sociales/ Proyecto financiado por medio del Programa de Apoyo a Proyectos de Investigación e Innovación Tecnológica (PAPIIT IG400813), donde el Dr. José Daniel Manzano Agulia era el profesor responsable.

10 Luis Serrano, es profesor de la FAD y coordinador del GIAE. Actualmente comparto la coordinación del GIAE_y realizamos muchas prácticas de colaboración, mediante la RED de Investigación Acción Colaborativa que propone el GIAE_. (https://giaiae.wordpress.com/red/), y sobre las cuales continuaremos hablaremos en diferentes momentos de este trabajo, fortaleciendo la argumentación de que el trabajo académico, es también producción cultural. 

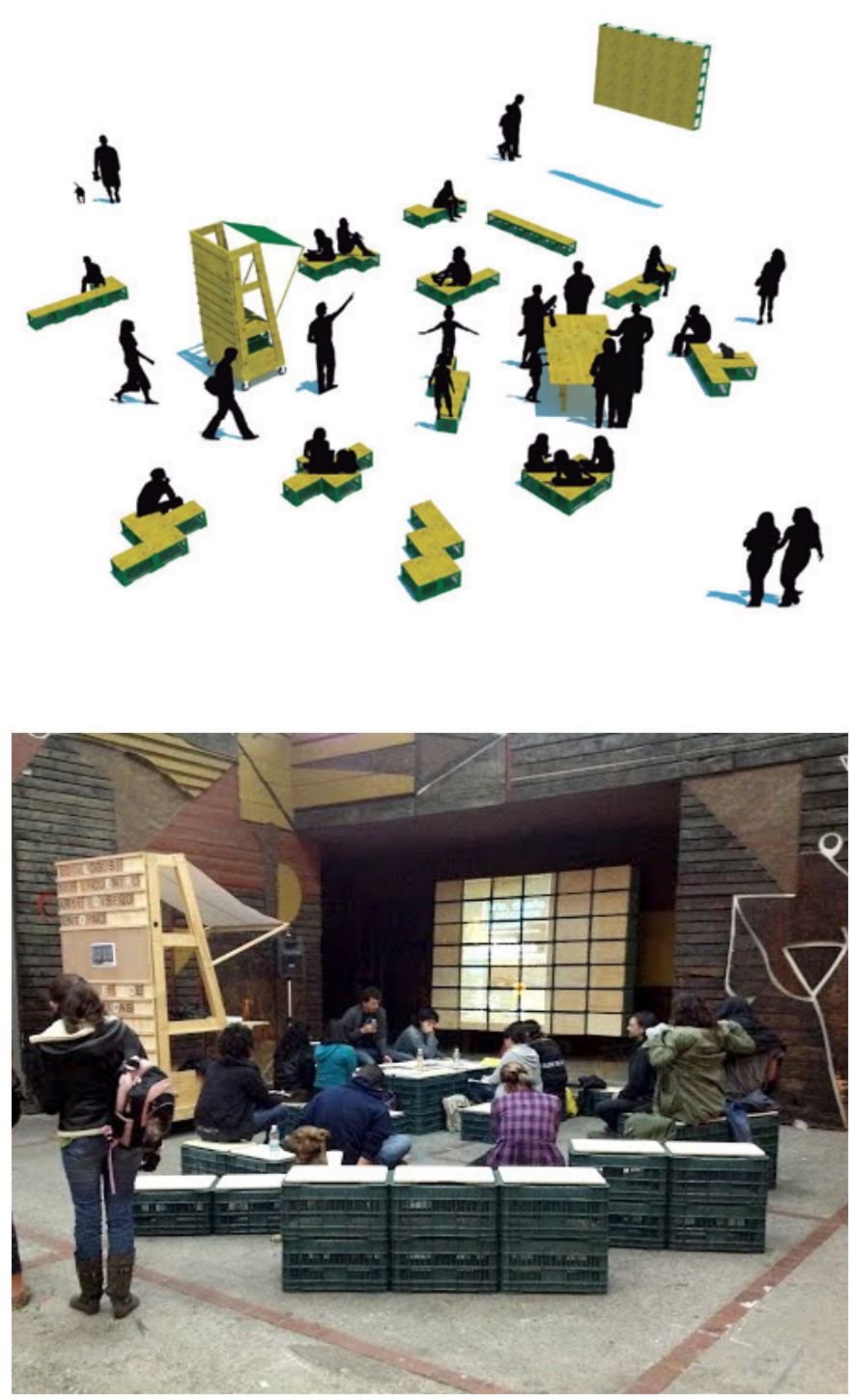

Imágenes 6 y 7. Diseño y activación en la Escuela Nacional de Artes Plásticas de la UNAM en el marco del Primer Encuentro de Arte-Diseño y Procesos Sociales en el 2014.
A partir de establecer la necesidad de producir cien módulos, debido a la diversidad de actividades, y al pensar el diseño como algo colectivo y abierto, se desarrolló un diseño de código abierto; ${ }^{11}$ de fácil fabricación para no excluir a ninguna persona de la posibilidad de fabricarlo por sí mismos, y se sociabilizó un esquema que se puede consultar en línea. ${ }^{12}$ Dicha acción, se suma al movimiento global maker, ${ }^{13}$ basado en la filosofía del código abierto, inicialmente surgido en las comunidades de desarrolladores de software libre, ${ }^{14}$ actualmente expandido a todo tipo de producciones, tales como obras de arte, diseño, ciencia, tecnología, etcétera, es decir, para la auto fabricación del llamado hardware.

Un ejemplo práctico e interesante para observar de hasta donde han llegado estas prácticas, la encontramos en un proyecto que plantea la creación de una civilización en código abierto; estamos hablando de Open Source Ecology, ${ }^{15}$ un espació que pretende desarrollar "[...] un conjunto de cincuenta modelos/máquinas fundamentales para la existencia de la vida moderna", desde un tractor, un horno, hasta un productor de circuitos"; es en este espíritu donde se inserta el Poliminó.

11 Si bien los derechos de autor le pertenecen a Yuri Aguilar, el diseño esta compartida bajo el copyleft, una práctica que consiste en permitir la libre distribución de copias o versiones modificadas de una obra u otro trabajo, exigiendo que los mismos derechos sean preservados en las versiones modificadas.

12 https://sites.google.com/view/yuriescultor/polimin $\% \mathrm{C}_{3} \% \mathrm{~B}_{3} /$ encuentro

13 Ver: http://www.makeatuvida.net/

14 Para conocer con mayor profundidad ver el video Richard Stallman ¿Que es el Software Libre? Disponible en: https://youtu.be/ OJqf_XoZiWg

15 Ver: http://opensourceecology.org/about-overview/ 
En las siguientes imágenes ( 8 y 9), observamos en la izquierda un esquema donde se dan instrucciones de una manera muy visual, respecto a cómo elaborar tus propios taburetes, en la fotografía del lado derecho (Imagen 9) vemos cómo Ciudad Emergente retoma esta propuesta y le hace una mejora, en vez de usar cajas agrarias, utiliza cajas refresqueras, que por su mayor altura resultan más cómodas para las personas, al tener una mejor proporción respecto el largo de las piernas. En el ámbito académico no se reconoce comúnmente las soluciones técnicas como conocimiento, sin embargo, argumentamos desde este ejemplo, el esquema de acción técnico como una forma de conocimiento en el diseño, y esta cita por Ciudad Emergente es muestra de ello.
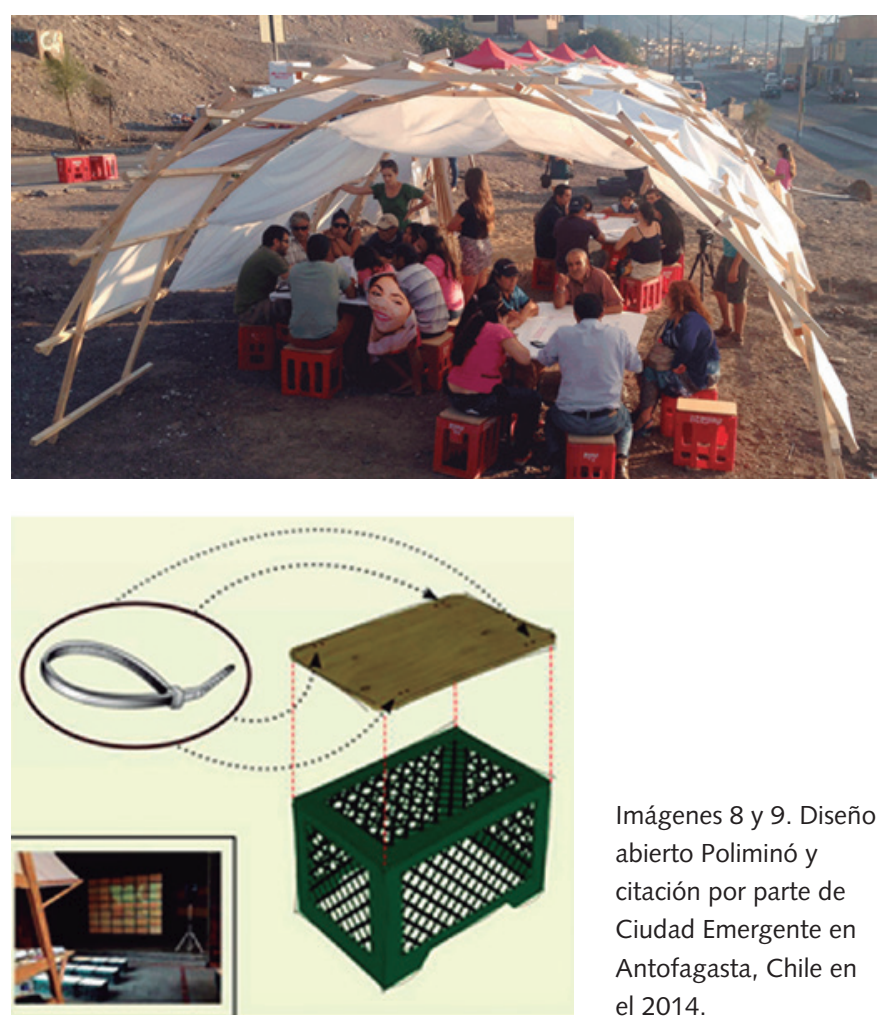

Imágenes 8 y 9 . Diseño abierto Poliminó y citación por parte de Ciudad Emergente en Antofagasta, Chile en el 2014.
El encuentro cultural al que nos hemos venido refiriendo, se comprende como un dispositivo para la extensión cultural de la comunidad universitaria, desde donde confrontar las investigaciones académicas por medio de la experimentación en el ámbito social. Dichas necesidades de configuración y reconfiguración obligaron la creación de mobiliarios compuestos, desde la utilización de un módulo como taburete o hasta cuarenta y dos elementos para la construcción de una pantalla para proyección de video.

Una de las principales características del código abierto, que ha impactado en las prácticas culturales emergentes, es el trabajo colaborativo, y en la arquitectura se presenta como construcciones colectivas. En el Poliminó el trabajo colectivo comenzó con la habilitación de un taller en una construcción en obra negra, que el Profesor Mayo, habitante del Pueblo de Santiago Tepalcatlalpan, nos facilitó. Se construyeron mesas de trabajo con madera donada por la Dirección General de Apoyo a la Comunidad Universitaria, de la UNAM, donde se estableció un sistema de producción en línea de trabajo. Iniciando la fabricación con el calado del triplay, posteriormente el lijado y las perforaciones para las sujeciones, y finalmente con el ensamblado de la madera sobre las cajas de plástico, en cada actividad participaron miembros del GIAE_, del Taller Imagen del Rinoceronte y vecinos del Pueblo de Santiago Tepalcatlalpan, así como, mi esposa Claudia.

El desbordamiento de la escultura hacia otros campos disciplinares como la arquitectura y el paisajismo, que Rosalind Kraus (1979) describió tan pertinentemente, y que Maderuelo (1990) lo calificó como el rapto del espacio por la escultura, dio como una de sus secuelas el desplazamiento de la arquitectura hacia el campo de las artes contemporáneas, que junto con el desarrollo de diseño y manufactura asistida por computadora han permitido estimular la creatividad hacia lugares donde cada vez es más difícil deslindar campos disciplinares. A partir 
de esta situación de crisis, se cuestionan todo tipo de presupuestos conceptuales arquitectónicos; uno de ellos es el hábitat construido, que convencionalmente lo asociamos a una casa, un edificio, una plaza, etcétera. Pero que el Poliminó mostró que los espacios habitables o habitáculos, son en realidad configuraciones espaciales que los usuarios significan mediante las actividades que se realizan en el lugar, pudiendo ser estas estructuras mínimas, es decir, sin paredes, sistemas hidráulicos u otros componentes de los grandes programas arquitectónicos. Así, cada taller, presentación o actividad que realizaron vecinos, artistas y colectivos, configuraba espacios propios a partir de necesidades específicas, dotándole de una flexibilidad característica de las estructuras modulares y móviles.

La noción de dispositivo se ha utilizado mucho en el arte/ diseño contemporáneo de manera superficial, hasta el punto de que hoy se le nombra dispositivo a una caja negra (Latour, 1992), como los teléfonos inteligentes, tabletas, artefactos móviles, etcétera, simplificando la complejidad del hecho cultural del dispositivo, a una mercancía. Sin embargo, el concepto de dispositivo al que me refiero y al que me he referido con anterioridad, es otro, el que Agamben (2011) nos comparte de la siguiente manera:

[...] se trata de un conjunto heterogéneo que incluye cada cosa, sea discursiva o no: discursos, instituciones, edificios, leyes, medidas policiacas, proposiciones filosóficas. El dispositivo, tomado en sí mismo, es la red que se tiende entre estos elementos.

Es decir, el dispositivo es el conjunto de todos los elementos que se utilizaron para el encuentro de arte, diseño y procesos sociales (gestiones + participación de las comunidades académicas, artísticas y ciudadanas + Poliminó + difusión en redes sociales + otros). De tal forma que, las arquitecturas colectivas son leídas como una de las interfaces de dicho dispositivo, es el mecanismo mediante el cual el dispositivo interactúa con las personas, en el caso del Poliminó es el elemento que permite la articulación de diversas disciplinas, facilitando un evento cultural extradisciplinar.

En este sentido de interfaz, se planteó otra experiencia de arquitectura colectiva, enmarcada en la "Fábrica de Cultura 'Hazlo Tú Mismo"', durante el 2015 y 2016, y donde se estableció la vinculación de trabajo colaborativo con el "Colectivo 'La Mulita Consentida", del Pueblo de San Pedro Mártir de la Ciudad de México, que planteaba inicialmente la construcción de una marquesina en el espacio independiente que gestionan, llamado "El Semillero" (Imagen 10).

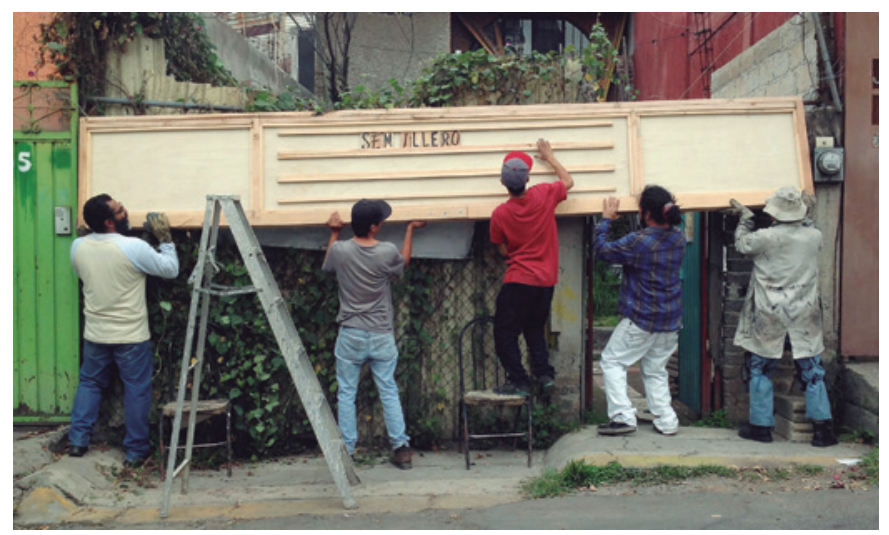

Imagen 10. Trabajo colaborativo en la colocación de la marquesina “El Semillero" de San Pedro Mártir en la Ciudad de México.

Se planteo como una interface donde comunicar sus actividades y poética a la comunidad con la cual trabaja. El proyecto creativo se abordaba desde un aprendizaje-servicio, y en relación con "[...] actividades que combinan el servicio a la comunidad con el aprendizaje reflexivo de conocimientos, habilidades y valores" (Puig et al., 2011: 52), y que plantea diversos perspectivas de aprendizaje, el aprender a ser uno 
mismo, el aprender a convivir, el aprender a formar parte de una sociedad, y el aprender a habitar en el mundo (Puig et al., 2011: 49-50).

El trabajo colaborativo se plantea diferenciado, porque ya no se trataba de crear un objeto como en los talleres comunitarios, ni establecer una plataforma para actividades diversas como el Poliminó, en esta ocasión se trataba de fortalecer un proyecto juvenil de integración comunitaria, en la que a partir del dialogo y la colaboración, se le daba sentido común al espacio, y donde la presencia del componente juventud, es pertinente resaltar. Así, el taller se desarrolló de manera muy participativa, mientras María, Joyce y Viridiana hacían las letras para formar los mensajes de la marquesina, Pedro, su "banda" y yo elaborábamos e instalábamos la marquesina, una tarea que requería de trabajo en equipo obligadamente, por su magnitud espacial y peso.

Después de haber terminado esta primera feliz intervención en "El Semillero", me propusieron continuar con toda la fachada del espacio, expandiendo la interface de su utilidad comunicativa, hacia la apertura mediante las puertas del estacionamiento para guardar su "Gatomóvil 1", y que también funcionaría como dispensario de pulque, el cual vendían todos los fines de semana como parte de su propuesta cultural; también se planteó la necesidad de enverdecer la fachada con paredes vegetales, así me di a la tarea de presentarles un diseño, que junto con ellos fuimos afinando hasta ejecutarlo en el 2016, y que incluía tres macetas en el lado izquierdo, y un portón dispensador de pulque, en el centro.

La experiencia de abordar la fachada como un trabajo, me permitió reflexionar en la utilidad de las arquitecturas colectivas para la transformación social, entendida desde el contexto de un proyecto de cultura comunitaria, en un espacio independiente y con jóvenes, como una construcción de nuestra propia realidad, tanto del colectivo y su interacción

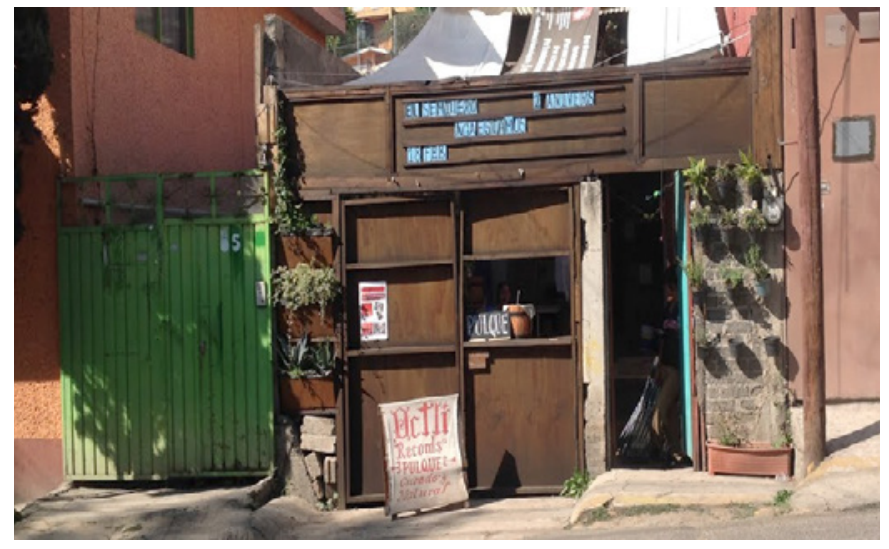

Imagen 11. Interfaz terminada en "El Semillero".

con la comunidad a partir de esta interfaz, así como de mí mismo, profundizando cada vez más, en la idea de la producción cultural como un hecho colectivo, algo que el propio "Colectivo 'La Mulita Consentida" ya sabía, y me enseñó a través de su acción.

Otra de las experimentaciones en las que participé, a propósito del tema de las arquitecturas colectivas, fue "La Okuplaza" UNAM-Santiago (Imagen 12), conceptualizada La Okuplaza por los creadores el colectivo chileno de "Ciudad Emergente" de esta forma:

Okuplaza es una intervención urbana creativa diseñada por Ciudad Emergente que busca ocupar lugares de la ciudad subutilizados transformándolos temporalmente en plazas y espacios públicos para las personas (Ciudad Emergente, 2017).

Enmarcada en la Primera Escuela de Otoño sobre Urbanismo Táctico en el 2014, organizado por el GIAE_ y Ciudad Emergente, es un emplazamiento con similares objetivos de vinculación académico-social que el Primer encuentro de arte-diseño 


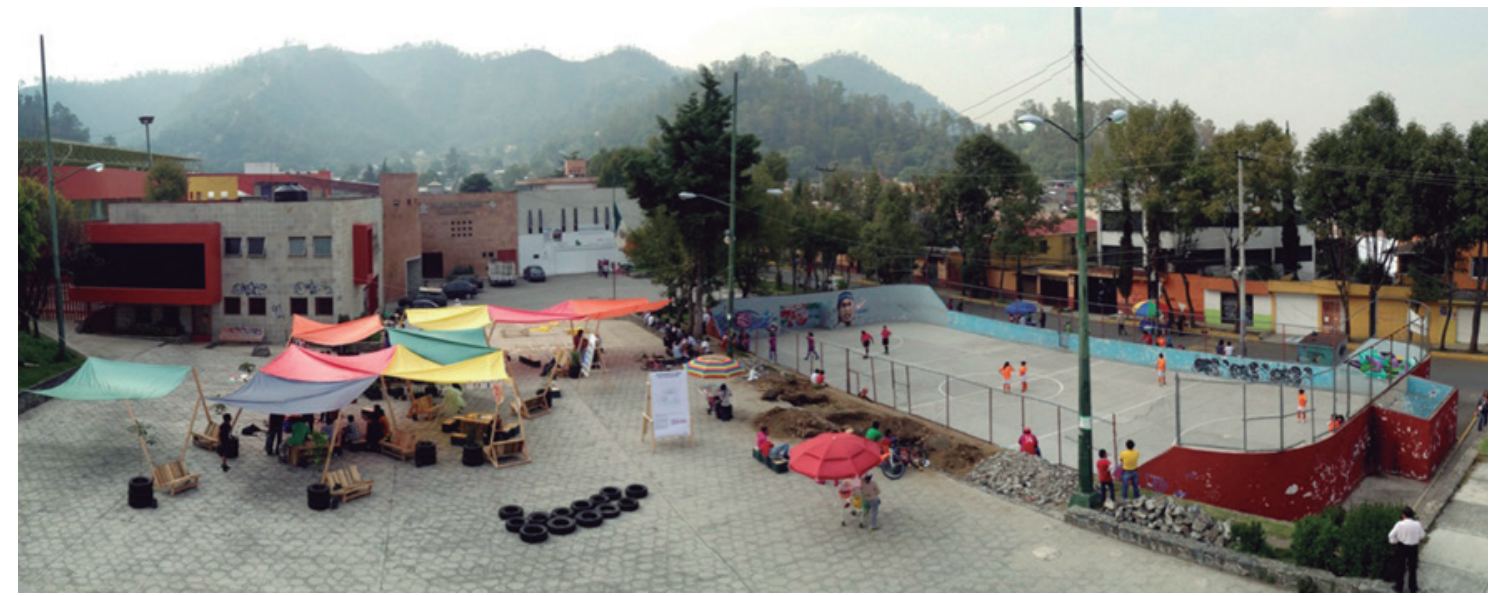

Imagen 12. La Okuplaza. UNAMSantiago en el Centro Cultura Santiago Tepalcatlalpan en la Delegación Xochimilco de la Ciudad de México 2014. y procesos sociales, pero esta vez abordado, desde las tácticas urbanas como herramienta de articulación entre conocimientos, saberes y experiencias. ${ }^{16}$ Resalto de esta experiencia la inclusión de colectivos de la sociedad civil, como "Isla Urbana" que acerco las tecnologías de cosecha de agua a la población, y la representación de la Comunidad de Santiago Tepalcatlalpan, que tuvo la oportunidad de difundir sus trabajos de conservación y manejo de su área natural y rural.

Esta ocupación temporal del espacio público también es comprendida desde la perspectiva de Bourriaud como un paréntesis espacial y temporal en la esfera social.

[...] es importante reconsiderar el lugar de las obras en el sistema global de la economía, simbólica o material, que rige la sociedad contemporánea: para nosotros, más allá de su carácter comercial o

16 Para conocer todos los colectivos y proyectos de investigación participantes consultar: https:/giaiae.wordpress.com/2014/10/31/1aescuela-de-otono-microurbanismo-tactico/ de su valor semántico, la obra de arte representa un intersticio social. Este término, "intersticio", fue usado por Karl Marx para definir comunidades de intercambio que escapaban al cuadro económico capitalista por no responder a la ley de la ganancia: trueque, ventas a pérdida, producciones autárquicas, etc. [...] El intersticio es un espacio para las relaciones humanas que sugiere posibilidades de intercambio distintas de las vigentes en este sistema, integrado de manera más o menos armoniosa y abierta en el sistema global. Este es justamente el carácter [...] [del] [...] arte contemporáneo [...] crear espacios libres, duraciones cuyo ritmo se contrapone al que impone la vida cotidiana, favorecer un intercambio humano diferente al de las "zonas de comunicación" impuestas (Bourriaud, 2008: 16).

Es el carácter de intersticio, que apertura espacios de relación no convencionales, le otorga al arte otra dimensión útil socialmente, desacelerando la vida cotidiana y privilegiando el intercambio humano complejo, recociéndonos como comunidad, implicándonos en los procesos compartidos, facilitando la divulgación de conocimientos y saberes. A este respecto, me gustaría compartir la participación de la integrante del GIAE_ 


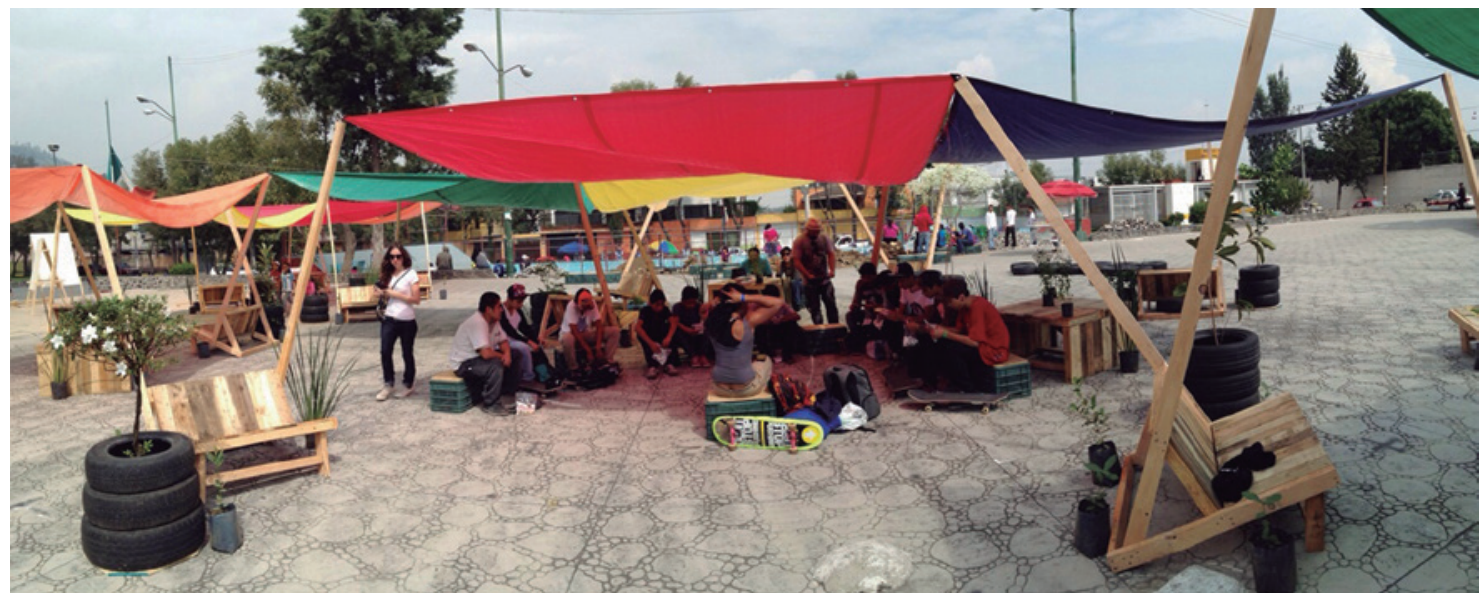

Imagen 13. Taller urbanskatemap en "La Okuplaza". UNAMSantiago en el Centro Cultura Santiago Tepalcatlalpan, Xochimilco Ciudad de México, 2014.
Ivonne Nava, quien desarrollo un taller de video para un grupo de jóvenes patinadores de Santiago Tepalcatlalpan (Taller urbanskatemap), ${ }^{17}$ quien en la mañana comenzó con un taller de un sujetador para celulares para grabar en movimiento sobre las patinetas, después a medio día se pusieron a grabar, y por la tarde se proyectaron los videos, todo sucedió en el marco de "La Okuplaza" (Imagen 13). Lo que se muestra claramente es cómo "La Okuplaza" es una táctica urbana que abre un espacio de intercambio humanizado, donde se desarrollan diversidad de formas relacionales, guiados por los intereses compartidos.

Finalmente, para pensar sobre otras dimensiones de la utilidad social del arte me referiré a la artista cubana Tania Brugera que aborda en su obra temas políticos y sociales a partir de las nociones de poder y control. Brugera plantea la idea de "arte útil”, que me permitirá establecer una discusión, tensión y reflexión sobre los alcances de esta utilidad.

17 Para ver un video resumen de esta actividad consultar en: https:// www.youtube.com/watch?v=UsRXcTC 3 iy 8
El impulso natural de un artista es tratar de comprender las cosas que lo rodean y compartir con los demás las preguntas que se hace y las respuestas que encuentra. El sentido del Arte Útil es imaginar, crear, desarrollar e implementar algo que, creado desde la práctica artística, brindar a la gente un resultado claramente beneficioso. Esto es arte porque es la elaboración de una propuesta que no existe todavía en el mundo real y porque es hecho con la esperanza y la creencia en que algo puede hacerse de un modo mejor, incluso cuando las condiciones no están aún allí para que así ocurra. El arte es el espacio a partir del cual uno se comporta como si existieran las condiciones para que ocurran las cosas que uno quiere que ocurran y como si todos estuvieran de acuerdo sobre lo que proponemos, aunque eso todavía no sea así, es vivir el futuro en el presente. El arte es también hacer creer, aunque sepamos que no tenemos mucho más que la creencia misma. El arte es ir practicando el futuro (Bruguera, 2012).

Ir practicando el futuro y hacer creer, son un punto de partida para explorar otras formas de la utilidad social del arte, de las cuales hemos hablando en este apartado, y sobre lo cual he 
de resaltar la capacidad del arte para generar vínculos sociales, para fortalecer lo que la jerga oficial y científica social llama, el tejido social. Lo cual me sugiere la comprensión sobre la vocación de la escultura social, no como la modelación de la sociedad al antojo del artistas, sino la participación del arte en un proceso participativo del desarrollo de las relaciones políticas entre individuos, el arte en este sentido es una actividad "trans", está en el medio de las personas, no es un mensaje o una expresión, es el puente con el cual se une a las colectividades, es la cultura que nos permite dialogar y hacer cosas juntas, pero también relacionarnos con el mundo, con lo no humano, el entorno, la naturaleza, lo otro que no somos, es una red de implicaciones "El arte es un estado de encuentro" (Bourriaud, 2008: 17). *

\section{REFERENCIAS}

Agamben, G. (2011). “¿Qué es un dispositivo?”. En Revista Sociológica, vol. 26, núm. 73, pp. 249-264.

Aguilar, Y. (2014). Fábrica de juguetes "Hazlo Tú Mismo". México. Aguilar, Y. y L. Serrano (2017). GIAE_. México: Laboratorio de Arte, Diseño y Entorno-UNAM.

Angrosino, M. (2012). Etnografía y observación participante en Investigación Cualitativa. Madrid: Ediciones Morata.

Beuys, J. (1977). Entrada en un ser vivo. Kassel: Documenta 6. Bourriaud, N. (2008). Estética relacional. Buenos Aires: Adriana Hidalgo. Bruguera, T. (2012). Reflexions on Arte útil (Useful Art). Madrid: Centro de Arte Dos de Mayo (CA2M)-Dirección General de Bellas Artes del Libro y de Archivos. Disponible en: http://www. biboloid.com/2013/o1/arte-util.html o http://www.taniabruguera. $\mathrm{com} / \mathrm{cms} / 592-$ - $-R e f l e x i o n s+o n+A r t e+t i l+U s e f u l+A r t . h t m$

Ciudad Emergente (2017). Okuplaza. Disponible en: http://okuplaza.org/ IDEO. (2015). The Field Guide to Human-Centered Design.

Krauss, R. (1979). "La escultura en su campo expandido". En H. Foster La posmodernidad. Barcelona: Kairos.

Latour, B. (1992). Ciencia en acción. Cómo seguir a los científicos e ingenieros a través de la sociedad. Barcelona: Editorial Labor.

Maderuelo, J. (1990). El espacio raptado: interferencias entre arquitectura y escultura. España: Mandadori.

Pérez, F. (2003). Lo material y lo inmaterial en el arte-diseño contemporáneo (materiales, objetos y lenguajes virtuales). México: Universidad Autónoma Metropolitana Unidad XochimilcoDivisión de Ciencias y Arte para el Diseño.

Puig, J., M. Gijón, X. García y L. Rubio (2011). “Aprendizaje-servicio y Educación para la Ciudadanía”. En Revista de Educación, pp. 45-67.

Sennett, R. (2012). Juntos: rituales placeres y política de cooperación. Barcelona: Anagrama.

Vidal, T., y E. Pol, (2005). "La apropiación del espacio: una propuesta teórica para comprender la vinculación entre las personas y los lugares". En Anaurio de Psicología, núm. 3. Barcelona: Universidad de Barcelona. 